\title{
The use of a DBT skills-based group in aiding with the inpatient and outpatient treatment demands of a specialized eating disorders unit
}

\author{
Lyndsey Nolan*, Sarah Mitchell \\ From 2013 ANZAED Conference: Inspiring Change: Person and Context \\ Melbourne, Australia. 23-24 August 2013
}

The Royal Melbourne Hospital provides inpatient, outpatient and day patient treatment to over 130 patients within the NorthWestern catchment area of Victoria each year. The RMH Eating Disorders Unit is the largest public inpatient service Room: State-wide offering 8 inpatient beds, with an average length of stay of 36 days. The severity, chronicity and complexity of emerging presentations has resulted in a greater demand for inpatient beds, exhausted wait lists, and placed further need and demand on outpatient and transitional support. The Dialectical Behavioural Therapy (DBT) group for Eating Disorders was developed and introduced to the Unit in mid-2011 as a means to provide support, treatment and relapse prevention to those patients who presented with borderline personality disorder (BPD) features and/or often required multiple admissions.

The DBT group is a skills-based closed group, which runs for 2.5 hours weekly for 15 weeks. The group focuses on psycho-education of eating disorders, mindfulness, emotional regulation, distress tolerance, and interpersonal effectiveness. Each cohort is evaluated using pre-test and post-test measures as well as weekly participation feedback. The outcome measures to date have shown that the DBT outpatient group has been effective in reducing BPD features and impulsive behaviours; created positive shifts in mood, unhelpful thought patterns and schemas; reduced stress and anxiety; and attributed to lower readmission rates.

This abstract was presented in the Adult Treatment and Services stream of the 2013 ANZAED Conference.

* Correspondence: Iyndsey.nolan@live.com.au

Eating Disorders Unit, NorthWestern Mental Health, Royal Melbourne Hospital, Australia

(c) 2013 Nolan and Mitchell; licensee BioMed Central Ltd. This is an Open Access article distributed under the terms of the Creative Commons Attribution License (http://creativecommons.org/licenses/by/2.0), which permits unrestricted use, distribution, and reproduction in any medium, provided the original work is properly cited.
doi:10.1186/2050-2974-1-S1-06

Cite this article as: Nolan and Mitchell: The use of a DBT skills-based group in aiding with the inpatient and outpatient treatment demands of a specialized eating disorders unit. Journal of Eating Disorders 2013 1(Suppl 1):O6.
Submit your next manuscript to BioMed Central and take full advantage of:

- Convenient online submission

- Thorough peer review

- No space constraints or color figure charges

- Immediate publication on acceptance

- Inclusion in PubMed, CAS, Scopus and Google Scholar

- Research which is freely available for redistribution
Biomed Central \\ () Biomed Central}

